\title{
Avaliação experimental de blocos prensados de solo-cimento com adição de grits
}

\author{
Experimental evaluation of pressed blocks of soil-cement \\ with grits addition
}

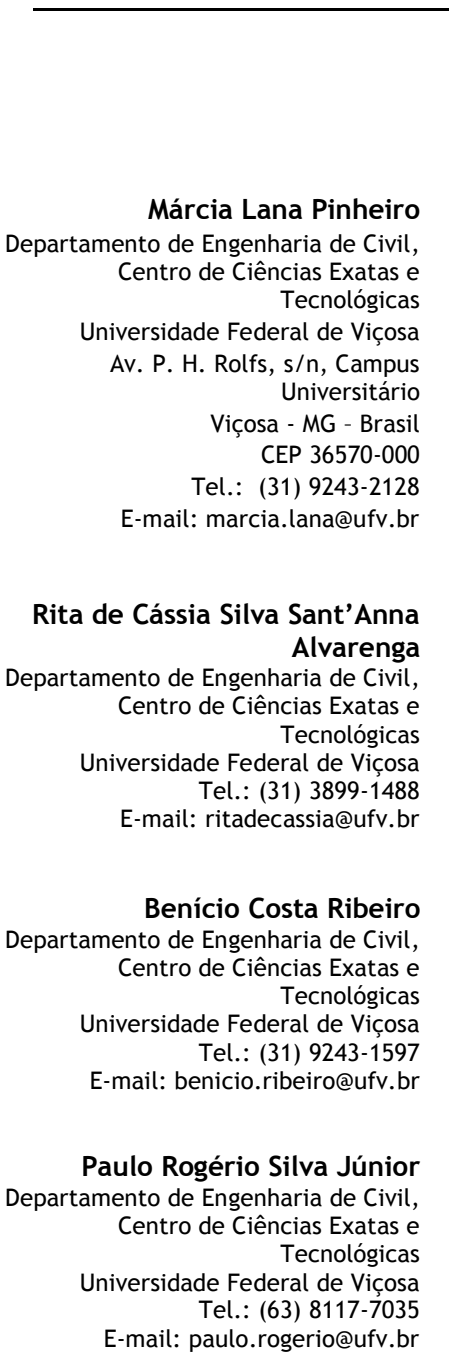

Márcio Sampaio Sarmet Departamento de Engenharia de Civil,

Centro de Ciências Exatas e Tecnológicas

Universidade Federal de Viçosa Tel.: (31) 3899-2724

E-mail: msarmet@ufv.br

Délio Porto Fassoni Departamento de Engenharia de Civil, Centro de Ciências Exatas e Tecnológicas

Universidade Federal de Viçosa Tel.: (31) 3899-3102

E-mail: delio@ufv.br

Recebido em 05/09/12

Aceito em 09/04/13

\section{Márcia Lana Pinheiro \\ Rita de Cássia Silva Sant'Anna Alvarenga \\ Benício Costa Ribeiro \\ Paulo Rogério Silva Júnior \\ Márcio Sampaio Sarmet \\ Délio Porto Fassoni}

\section{Resumo}

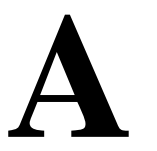

produção de resíduos pelas indústrias de papel e celulose vem crescendo continuamente, gerando custos com estocagem e aumentando os impactos ambientais. O presente trabalho teve como objetivo estudar a viabilidade de incorporação do resíduo grits, oriundo dessas indústrias, na fabricação de blocos prensados de encaixe de solocimento, como um novo material de construção. Foi verificada a maior quantidade de resíduo possível de ser utilizada, respeitando-se as exigências normativas. Para tanto, realizou-se caracterização física e mecânica de diversas proporções de sologrits e foram fabricados blocos com as proporções investigadas. Após a cura, foram realizados, além de outros, os ensaios de resistência à compressão e absorção de água. Em relação à caracterização física, constatou-se que todos os teores de solo-grits atenderam às exigências normativas. Com relação à resistência à compressão e absorção de água, tem-se que as percentagens com plasticidade suficiente para fabricar os blocos também atenderam às exigências normativas. A porcentagem em massa de 37,5-62,5 de solo-grits pode ser definida como o teor que utiliza a maior quantidade de resíduo e tem plasticidade mínima necessária para a fabricação de blocos. Portanto, o uso do grits na produção de blocos de solocimento surge como uma tecnologia viável, além de minimizar a degradação ambiental.

Palavras-chave: Grits. Bloco prensado de encaixe. Solo-cimento. Habitação de interesse social.

\section{Abstract}

The production of waste by the paper and cellulose industry has been growing continuously, generating storage costs and increasing environmental impact. The aim of this paper is to verify the viability of incorporating the grits waste, produced by that industry, in the manufacture of pressed soil-cement blocks that key together as a new building material. The highest quantity of waste that could be used was verified, complying with the normative requirements. In order to do that, the physical and mechanical characteristics of the soil with different content of grits were determined and blocks with different soil-grit proportions were produced. After curing, different tests were carried out, including compressive strength and water absorption tests. Regarding the physical characteristics, the conclusion was made that all the soil-grits ratios meet the normative requirements. As for compressive strength and water absorption, the results showed that the percentages of soil-grits that had enough plasticity for manufacturing blocks meet the normative requirements. The weight proportion of 37.5-62.5 soil-grits can be defined as the ratio with highest waste content and minimum plasticity required to make the blocks. Therefore, the use of grits in the production of soil-cement blocks emerges as a viable technology, which may have a positive environmental impact.

Keywords: Grits. Pressed socket blocks. Soil-cement. Housing of social interest. 


\section{Introdução}

A NBR 10004 (ABNT, 2004a) define resíduos sólidos como resíduos nos estados sólido e semissólido que resultam de atividades de origem industrial, doméstica, hospitalar, comercial, agrícola, de serviços e de varrição. Ela classifica esses resíduos quanto aos riscos potenciais ao meio ambiente e à saúde pública em dois grupos: perigosos e não perigosos. Os perigosos são da classe I, e os não perigosos, da classe II, sendo ainda este último grupo subdividido em não inerte (classe II A) e inerte (classe II B).

Se o resíduo não tem características de inflamabilidade, corrosividade, reatividade, toxicidade ou patogenicidade, ele é de classe I; se tiver alguma dessas características, é de classe II. Se o resíduo de classe II possui constituintes que são solubilizados em concentrações inferiores ao Anexo G da NBR 10004 (ABNT, 2004a), ele é de classe II A; se possui constituintes que são solubilizados em concentrações superiores, é de classe II B.

O grits é um resíduo sólido gerado pelas indústrias de celulose e papel mediante o processo Kraft de recuperação química dos compostos utilizados na produção de celulose. Uma das etapas de recuperação é a calcificação, que dá origem ao resíduo grits, conforme a Figura 1. Segundo Souza e Cardoso (2008), o grits é de classe II A.

De características arenosas e coloração acinzentada, o grits apresenta, segundo Machado, Pereira e Pires (2003), 20\% de Ca (cálcio), sendo $42 \%$ deste na forma de $\mathrm{CaO}$ (óxido de cálcio), $79 \%$ de sílica ( $\mathrm{SiO} 2)$, que são os compostos mais abundantes no cimento. Segundo Petrucci (1998), os componentes principais do cimento Portland, cuja determinação é feita a partir de análises químicas, são cal $(\mathrm{CaO})$, sílica $(\mathrm{SiO} 2)$, alumina (A12O3), óxido de ferro (Fe2O3), magnésia $(\mathrm{MgO})$, álcalis ( $\mathrm{Na} 2 \mathrm{O}$ e $\mathrm{K} 2 \mathrm{O})$ e sulfatos (SO3). Destes, os componentes encontrados em maior quantidade são a cal, numa porcentagem de $60 \%$ a $67 \%$, e a sílica, variando de $17 \%$ a $25 \%$.

A produção de resíduos pelas indústrias de papel e celulose vem crescendo continuamente, gerando gastos com estocagem ou aumentando os impactos ambientais, visto que esses materiais são destinados aos aterros. O aproveitamento desses resíduos como material de construção para a produção de novas tecnologias para a construção civil representa a minimização dos danos ambientais, além de ser uma alternativa para a redução do déficit habitacional.

Dessa forma, a incorporação do resíduo grits na fabricação de blocos prensados de encaixe de solocimento surge como uma tecnologia viável sob o ponto de vista técnico e econômico, além de minimizar a degradação ambiental, causada pelos aterros e uso de recursos naturais, como jazidas de solo.

Existem na literatura diversos trabalhos enfocando a utilização do grits, aproveitando-o como estabilizante dos solos e incorporando-o em materiais cerâmicos, entre outras aplicações na construção civil.

De acordo com Pereira, Machado e Carvalho (2006), o grits apresentou potencial significativo como estabilizante dos solos. A adição do grits permitiu ganhos de resistência mecânica nos solos, principalmente para os de textura arenossiltoargilosa. Os resultados obtidos para misturas com teores superiores a $8 \%$ de grits as qualificam como camadas de sub-base para pavimentos flexíveis segundo o método do Departamento Nacional de Infraestrutura de Transportes (DNIT). Segundo Machado et al. (2007), o grits apresentou-se potencialmente utilizável como agente estabilizante de solo (latossolo) para pavimento de estradas florestais, sendo mais eficiente após o tratamento térmico do grits a $600{ }^{\circ} \mathrm{C}$. Conforme Machado et al. (2009), dentro do comportamento geotécnico de misturas granulométricas de solo-grits, os resultados apontaram que a fração fina do grits é a mais importante para ganho de resistência mecânica, demonstrando sua importância na reatividade das misturas, sendo que a fração pedregulho exerce menor influência nos ganhos de resistência mecânica dos solos.

Ribeiro (2010) avaliaram os resíduos grits e dregs física e quimicamente para incorporá-los em massa cerâmica em diversas proporções. Queimados, os corpos de prova tiveram suas propriedades cerâmicas medidas e foram também investigadas as causas dos resultados obtidos por meio de métodos como difração de raios $\mathrm{X}$, análise térmica diferencial e microscopia eletrônica de varredura. Ensaios de solubilização foram feitos sobre os resíduos e corpos de prova para investigar os materiais quanto à inércia química. Resultados foram positivos para determinadas formulações. 


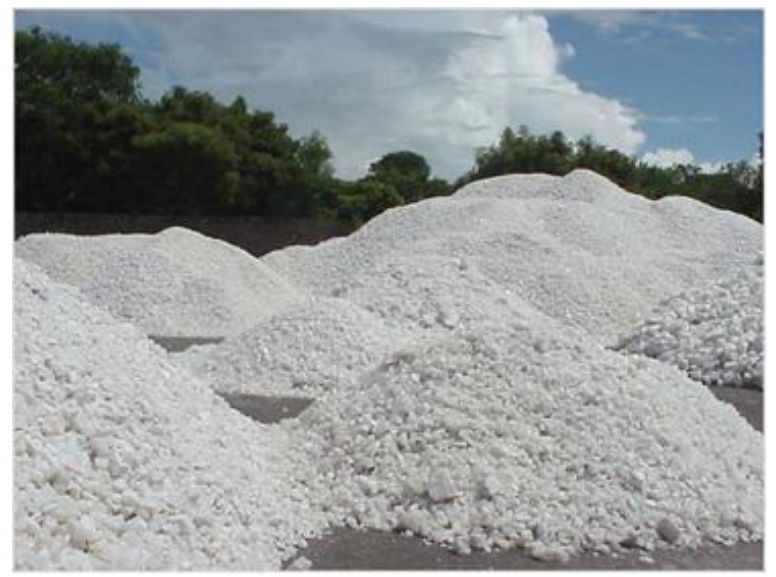

Figura 1 - Resíduo produzido pela indústria de celulose e papel (grits)

\section{Objetivo}

O presente trabalho teve como objetivo avaliar a viabilidade de incorporação do resíduo grits na fabricação de blocos prensados de encaixe de solocimento, com a finalidade de se obter um máximo consumo de resíduo, respeitando as exigências normativas. Dessa forma, os objetivos específicos foram:

(a) realizar a caracterização física de diversos teores solo-grits;

(b) verificar a umidade ótima de forma a obter blocos de resistência adequada, com esforço possível de ser realizado por uma pessoa em uma prensa manual, para diversos teores de solo-grits;

(c) moldar e ensaiar blocos prensados de encaixe de grits-solo-cimento, para diversos teores de sologrits;

(d) estudar o traço mais adequado, visando atender às exigências da NBR 10834 (ABNT, 1994) quanto à resistência mecânica e à absorção de água, com maior economia de cimento; e

(e) realizar a análise química do grits e dos extratos lixiviados e solubilizados de grits-solocimento do traço mais adequado, com a finalidade de classificar a mistura de acordo com a NBR 10004 (ABNT, 2004a) quanto a seus riscos potenciais ao meio ambiente e à saúde pública, para que possam ser gerenciados adequadamente.

\section{Materiais e métodos}

Para verificar a maior quantidade de resíduo a ser utilizada, respeitando-se as exigências normativas, foram analisados diversos teores em massa, correspondentes às porcentagens 100-0, 75-25, 5050, 25-75 e 0-100 de solo-grits.
A NBR 10834 (ABNT, 1994a) não cita as condições exigíveis para a fabricação de blocos prensados de encaixe de solo-cimento. Dessa forma, foram consideradas as mesmas prescrições da NBR 10832 (ABNT, 1989), que fixa as condições exigíveis para a produção de tijolos maciços de solo-cimento.

Para o presente trabalho, foi realizada a caracterização física do solo variando-se o teor de grits, mediante ensaios de massa específica dos sólidos, análise granulométrica e limites de consistência, além do ensaio de compactação e do ensaio da caixa, usado para medir a retração de solos.

Posteriormente, foram fabricados os blocos de encaixe para os diversos teores, em massa, de sologrits. Após a cura, foram realizados os ensaios de resistência à compressão e absorção de água.

A partir dos resultados obtidos, definiu-se o traço mais adequado, de maneira a atender às condições específicas da NBR 10834 (ABNT, 1994a) quanto à resistência à compressão e à absorção de água, e com maior economia de cimento. Para esse traço, foi realizada a análise química do grits e dos extratos lixiviados e solubilizados de grits-solocimento do traço mais adequado.

\section{Análise granulométrica}

A execução do ensaio de análise granulométrica ocorreu conforme os procedimentos da NBR 7181 (ABNT, 1984a).

Para a execução do ensaio foi necessário preparar a amostra. Inicialmente, o material foi passado na peneira de 2,0 $\mathrm{mm}$, tomando-se a precaução de desmanchar no almofariz todos os torrões eventualmente existentes, de modo a assegurar a retenção na peneira somente dos grãos maiores que a abertura da malha. Posteriormente, a parte retida 
foi lavada, a fim de eliminar o material fino aderente, e levada à estufa, até a constância de massa. Utilizando-se agitador mecânico, esse material foi passado nas peneiras de $50,38,25,19$, 9,5, 4,8 e 2,0 $\mathrm{mm}$. Determinou-se a massa retida em cada peneira e, assim, calcularam-se a massa e a porcentagem passante nas mesmas. Com esses valores, determinou-se a parte da curva granulométrica relativa à fração grossa do solo.

Para a determinação da parte da curva granulométrica relativa à fração fina do solo, o material passante na peneira de $2,0 \mathrm{~mm}$ foi lavado na peneira de $0,075 \mathrm{~mm}$, e a parte retida foi seca em estufa até a constância de massa. Utilizando-se o agitador mecânico, esse material foi passado nas peneiras de $1,2,0,6,0,42,0,25,0,15$ e $0,075 \mathrm{~mm}$. Determinou-se a massa retida em cada peneira e, assim, calcularam-se a massa e a porcentagem passante nas mesmas.

Para a determinação da parte da curva granulométrica relativa à fração fina do solo, cujos diâmetros das partículas são inferiores a 0,075 $\mathrm{mm}$, o material passante na peneira de $2,0 \mathrm{~mm}$ foi colocado em repouso com defloculante. Posteriormente, a mistura foi agitada no dispersor elétrico, transferida para a proveta graduada, sendo completada com água destilada até $1.000 \mathrm{~mL}$ e agitada de modo a obter uma mistura homogênea. Colocou-se a proveta sobre uma mesa e efetuaramse leituras do densímetro nos instantes de $30 \mathrm{~s}$ e 1 , 2, 4, 8, 15 e 30 min, e 1, 2, 4, 8 e 25 h. Assim, calculou-se a porcentagem de partículas de cada diâmetro.

\section{Determinação do limite de liquidez}

O ensaio para determinação do limite de liquidez foi executado conforme os procedimentos da NBR 6459 (ABNT, 1984b).

Acrescentou-se água destilada a uma quantidade de solo passante na peneira de 0,42 $\mathrm{mm}$, misturando-se até obter uma pasta homogênea. Transferiu-se parte da mistura para a concha, moldando-se de forma que na parte central a espessura fosse da ordem de $10 \mathrm{~mm}$. A massa de solo foi dividida em duas partes, passando-se o cinzel através da mesma, de maneira a abrir uma ranhura em sua parte central. A concha foi colocada no aparelho, golpeando-a contra a base. Foi deixado que ela caísse em queda livre, girando-se a manivela à razão de duas voltas por segundo. Anotou-se o número de golpes necessários para que as bordas inferiores da ranhura se unissem ao longo de $13 \mathrm{~mm}$ de comprimento, aproximadamente, e transferiu-se uma pequena quantidade do material de junto das bordas, que se uniram em um recipiente adequado, para determinação da umidade. $\mathrm{O}$ processo foi repetido para diversos teores de umidade, que forneceram diferentes números de golpes no intervalo entre 15 e 35 .

Com os resultados obtidos, foi construído um gráfico no qual as abscissas são os números de golpes e as ordenadas são os teores de umidade correspondentes, e, em seguida, foi ajustada uma reta pelos pontos assim obtidos. $\mathrm{O}$ valor do teor de umidade correspondente a 25 golpes foi definido como limite de liquidez do solo.

\section{Determinação do limite de plasticidade e índice de plasticidade}

O ensaio para determinação do limite e do índice de plasticidade foi executado conforme os procedimentos da NBR 7180 (ABNT, 1984c).

Acrescentou-se água destilada a uma quantidade de solo passante na peneira de $0,42 \mathrm{~mm}$, misturando-se de modo a obter uma pasta homogênea. Transferiu-se parte da mistura para uma placa de vidro, moldando-se para obter um cilindro. Quando se fragmentou um cilindro, com diâmetro de 3 mm e comprimento da ordem de 100 $\mathrm{mm}$, foram transferidas as partes dele para um recipiente adequado, para a determinação da umidade. O processo foi repetido algumas vezes, de modo a obter pelo menos três valores de umidade, não diferentes da respectiva média em mais de 5\%. A média dos valores de umidade obtidos foi tomada como o valor correspondente ao limite de plasticidade.

Com a diferença entre os valores de limite de liquidez e limite de plasticidade foi definido o índice de plasticidade.

\section{Ensaio prático da caixa}

O ensaio da caixa foi executado conforme um método prático e não normalizado, sugerido pelo Centro de Pesquisa e Desenvolvimento (Ceped) (1978).

Acrescentou-se água a uma quantidade de solo até atingir a consistência de uma argamassa de emboço. A mistura foi colocada em uma pequena caixa de madeira de $(8,5 \times 3,5 \times 60) \mathrm{cm}$ coberta com papel-manteiga. Para adensar a massa, a caixa foi levantada em uma de suas extremidades até uma altura de cerca de $5 \mathrm{~cm}$, deixando-se que ela caísse por 10 vezes, repetindo-se o procedimento na outra extremidade. Regularizou-se, então, a superfície da massa passando uma régua seguida de uma colher de pedreiro. A caixa foi deixada secando à sombra e ao abrigo das intempéries por 
7 dias. Ao fim desse período mediu-se a retração total do corpo de prova na direção longitudinal.

\section{Ensaio de compactação}

O ensaio para determinação da umidade ótima e do peso específico seco máximo foi executado conforme os procedimentos da NBR 7182 (ABNT, 1984d).

Para a execução do ensaio foi necessário preparar as amostras. Assim, o material foi passado na peneira de $4,8 \mathrm{~mm}$, tomando-se a precaução de desmanchar os torrões eventualmente existentes. Cada amostra de aproximadamente $3 \mathrm{~kg}$ foi colocada em uma bandeja metálica, adicionando-se água destilada gradativamente enquanto se revolvia continuamente o material. Pretendeu-se obter teores de umidade em torno de $5 \%, 3 \%$ e $1 \%$ abaixo da umidade ótima presumível nas três primeiras bandejas respectivamente, e nas duas últimas, teores de umidade em torno de $1 \%$ e $3 \%$ respectivamente, acima da umidade ótima presumível. A umidade ótima foi presumida com base na experiência dos profissionais envolvidos na pesquisa. O material de cada bandeja foi colocado em um saco plástico vedado e mantido em processo de cura em câmara úmida durante 24 h.

Após o processo de cura, foi dado início ao ensaio de compactação na energia normal (Proctor Normal). Cada amostra úmida foi compactada no interior de um molde cilíndrico, firmemente afixado a sua base e com o colarinho complementar ajustado, em três camadas sucessivas. Em cada camada foram dados 26 golpes com o soquete metálico, em queda livre de $305 \mathrm{~mm} \pm 1 \mathrm{~mm}$, em relação ao topo da camada, sendo os golpes distribuídos uniformemente sobre a superfície desta. Após a compactação, o colarinho foi removido, e o material rasado cuidadosamente com régua, de modo a se obter uma superfície lisa e nivelada com o topo do molde. Retirou-se a base destacável e determinouse a massa do conjunto molde-amostra compactada úmida e a umidade da amostra úmida. Com esses valores, calculou-se a massa específica seca da amostra.

Com os resultados obtidos, foi construído um gráfico no qual as ordenadas são as massas específicas secas, e as abscissas, as umidades correspondentes; em seguida, foi ajustada uma curva pelos pontos assim obtidos. A massa específica seca máxima é definida como sendo a máxima ordenada da curva, e a umidade ótima, o valor da umidade correspondente a esta ordenada.

\section{Fabricação dos blocos}

Os blocos foram fabricados de acordo com a NBR 10832 (ABNT, 1989). Partiu-se de um traço-base em massa de 1:10, de cimento e solo respectivamente. Inicialmente, pretendia-se fabricar blocos com diversos teores de solo-grits, em massa, correspondentes às porcentagens de $100-0,75-25,50-50,25-75$ e 0-100. No entanto, durante o processo de fabricação, observou-se que não foi possível retirar da prensa os blocos com $75 \%$ e $100 \%$ de grits em substituição ao solo. Assim, em uma segunda etapa foram fabricados blocos com o teor de $37,5 \%$ de solo e $62,5 \%$ de grits.

Para a confecção dos traços, dosados em massa, foram misturados o solo, o grits e o cimento até coloração uniforme (Figura 2a e 2b) e, então, foi acrescentada água em quantidade suficiente para se atingir a umidade desejada (Figura 2c), de acordo com o ensaio de compactação. A mistura foi colocada na prensa que dá forma aos blocos, sendo retirado o excesso antes da prensagem (Figura 2d). Logo após a prensagem, os blocos produzidos foram retirados da prensa, transportados em bandeja para a área de cura e colocados à sombra sobre uma superfície plana (Figuras 2e e 2f). Após $6 \mathrm{~h}$ da moldagem e durante os 7 primeiros dias, os blocos foram mantidos úmidos, a fim de garantir a cura necessária.

\section{Resistência à compressão e absorção de água}

Para procedimento de dosagem, a NBR 10834 (ABNT, 1994a) exige que, da amostra representativa, metade seja submetida ao ensaio de compressão e a outra metade ao ensaio de absorção de água. Dessa forma, foram submetidos três corpos de prova ao ensaio de resistência à compressão e três corpos de prova ao ensaio de absorção de água.

Os ensaios para determinação da resistência à compressão e absorção de água foram executados conforme os procedimentos da NBR 10836 (ABNT, 1994b).

\section{Resistência à compressão}

Primeiramente, os blocos foram medidos e, para cada dimensão de uma face de trabalho, foi adotada a média dos valores determinados em três posições diferentes. As medidas foram efetuadas com precisão de $1 \mathrm{~mm}$. 


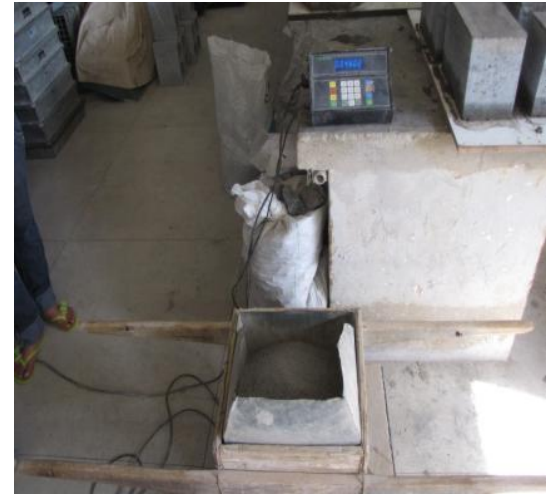

(a)

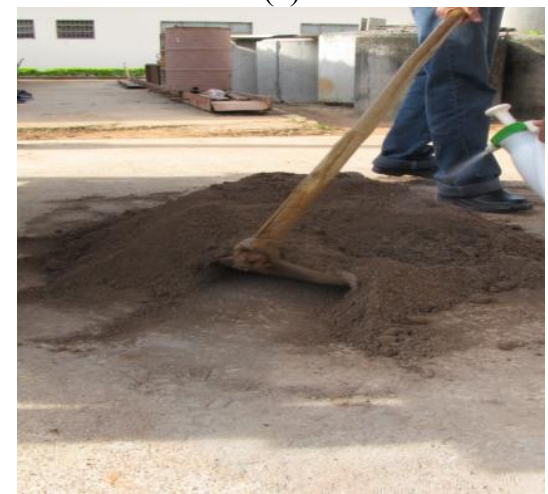

(c)

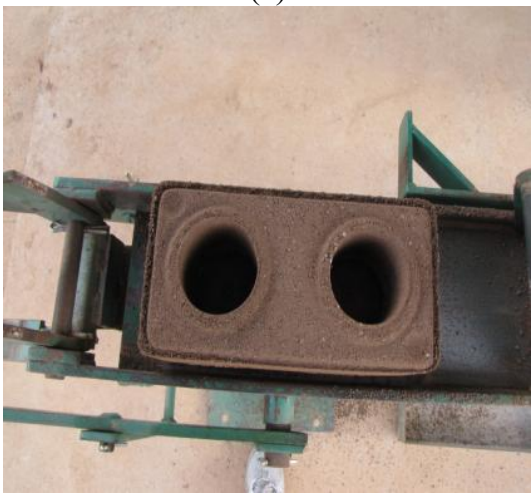

(e)

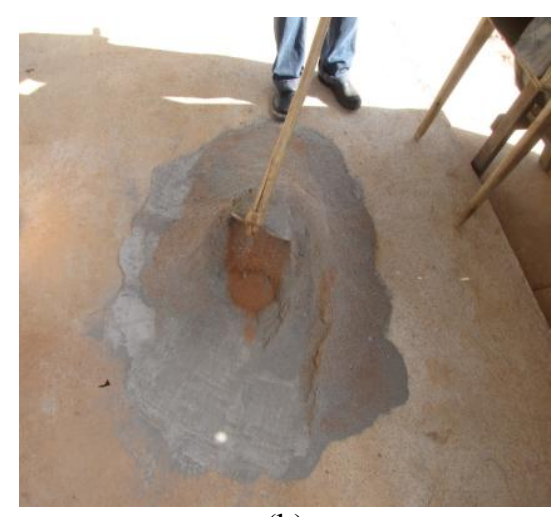

(b)

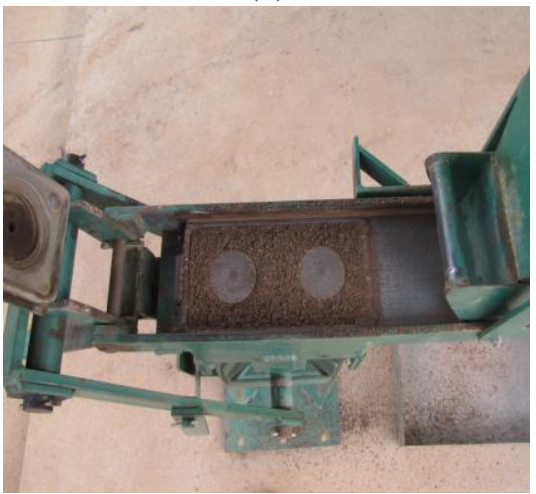

(d)

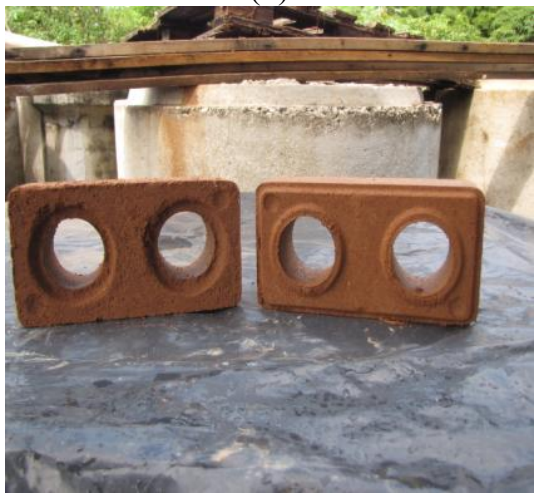

(f)

Figura 2 - Processo de fabricação dos blocos prensados de encaixe de solo-cimento com adição de grits

Posteriormente, foi feito o capeamento das faces de trabalho com argamassa de cimento Portland de consistência plástica, com espessura mínima necessária para que se obtenham faces planas e paralelas. Após o endurecimento do material de capeamento, os blocos foram ligados aos pares com uma camada de pasta de cimento Portland, pré-contraída (repouso de aproximadamente 30 $\mathrm{min}$ ), de $2 \mathrm{~mm}$ a $3 \mathrm{~mm}$ de espessura. Depois do endurecimento da pasta, os corpos de prova foram imersos em água por $24 \mathrm{~h}$, tendo sido retirados da água e enxugados superficialmente, imediatamente antes do ensaio.

O corpo de prova foi colocado diretamente sobre o prato inferior da máquina de ensaio, posicionado centrado em relação a ele. Em seguida, iniciou-se a aplicação de carga vertical, de forma lenta e gradual, à razão de $0,5 \mathrm{kN} / \mathrm{s}$. A carga foi crescente até a ruptura do corpo de prova.

A resistência à compressão, expressa em $\mathrm{MPa}$, de cada corpo de prova foi obtida dividindo-se a carga máxima, em Newtons, pela média das áreas das duas faces de trabalho, em milímetros quadrados. A resistência média dos corpos de prova foi obtida pela média das tensões de ruptura.

\section{Absorção de água}

Os corpos de prova foram colocados em estufa a uma temperatura entre $100{ }^{\circ} \mathrm{C}$ e $110^{\circ} \mathrm{C}$ até a

34 Pinheiro, M. L.; Alvarenga, R. de C. S.; Ribeiro, B. C.; Silva Júnior, P. R.; Sarmet, M. S.; Fassoni, D. P. 
constância de massa, obtendo-se a massa seca $\mathrm{M}_{1}$, em g. Posteriormente, os corpos de prova foram imersos em um tanque com água à temperatura ambiente durante $24 \mathrm{~h}$. Depois de retirados da imersão, os blocos foram enxugados com um pano úmido, sendo então determinada a massa $\mathbf{M}_{2}$, em gramas, antes de decorridos $3 \mathrm{~min}$.

O valor da absorção $(A)$, expresso em porcentagem, para cada corpo de prova, foi obtido pela Equação 1, e a absorção média foi obtida pela média dos valores individuais:

$$
A(\%)=\frac{M_{2}-M_{1}}{M_{1}} 100 \%
$$

\section{Análise química do grits}

Para fazer a leitura por absorção atômica dos metais que se pretendia encontrar no grits foi realizada a digestão da amostra no equipamento ETHOS 1, que funciona emitindo micro-ondas.

Antes de colocar o grits nos tubos do ETHOS 1, foi feita a limpeza deles adicionando-se $5 \mathrm{~mL}$ de ácido clorídrico em cada tubo, volume que foi mantido por $10 \mathrm{~min}$ dentro do equipamento em funcionamento. Assim, a temperatura e a pressão interna dentro dos tubos aumentaram devido à emissão das micro-ondas. Posteriormente, esperou-se que a temperatura interna dos tubos reduzisse para $40^{\circ} \mathrm{C}$, para que eles pudessem ser abertos e limpos.

Após a limpeza dos tubos, prepararam-se 5 amostras contendo: $4 \mathrm{~mL}$ de ácido nítrico a $65 \%, 2$ $\mathrm{mL}$ de ácido clorídrico e $2 \mathrm{~mL}$ de peróxido de hidrogênio a 30\%. Em 4 dessas amostras adicionou-se aproximadamente $0,25 \mathrm{~g}$ de grits, conforme a Tabela 1. A amostra que não continha grits foi denominada amostra branca, que teve a finalidade de avaliar a interferência dos reagentes utilizados em cada tubo em relação aos compostos que se queria determinar.

Posteriormente, os tubos foram colocados dentro do equipamento de digestão atômica, onde foi realizada a abertura das amostras por incidência das micro-ondas, que tem por objetivo a ionização das mesmas para realização da leitura dos metais. Após a digestão, cada amostra foi colocada em um balão volumétrico e adicionou-se água destilada até a obtenção de um volume de $25 \mathrm{~mL}$. Em seguida, as amostras foram colocadas no espectrômetro de absorção atômica para se proceder à leitura dos metais.

$\mathrm{O}$ valor do teor $(\mathrm{T})$ de cada metal encontrado em cada amostra, expresso em $\mu \mathrm{g} / \mathrm{g}$, foi obtido pela Equação 2:

$T(\mu g / g)=\frac{F_{d} V_{0}\left(L_{a}+L_{b}\right)}{M}$ Eq. 2

Onde:

$F_{d}$ : fator de diluição;

$V_{0}$ : volume da amostra;

$L_{a}+L_{b}$ : leitura dos metais; e

$M$ : massa da amostra.

$\mathrm{O}$ valor do teor médio $\left(\mathrm{T}_{\mathrm{m}}\right)$ de cada metal, expresso em $\mu \mathrm{g} / \mathrm{g}$, foi obtido pela Equação 3:

$T_{m}=\frac{T_{1}+T_{2}+T_{3}+T_{4}}{4}-T_{5}$

Eq. 3

Onde:

$T_{1}$ : teor do metal encontrado na amostra 1 ;

$T_{2}$ : teor do metal encontrado na amostra 2;

$T_{3}$ : teor do metal encontrado na amostra 3;

$T_{4}$ : teor do metal encontrado na amostra 4; e

$T_{5}$ : teor do metal encontrado na amostra 5 (amostra branca).

O valor do teor médio de cada metal é a média do valor do teor (T) de cada metal encontrado em cada amostra.

\section{Lixiviação do solo-cimento com adição de grits}

Com o traço mais adequado que atendeu às condições específicas da NBR 10834 (ABNT, 1994a) quanto à resistência à compressão e absorção de água, e com maior economia de cimento, foi realizado o ensaio de lixiviação, conforme os procedimentos da NBR 10005 (ABNT, 2004b).

Tabela 1 - Amostras para análise química

\begin{tabular}{c|c|c|c|c}
\hline Amostra & $\begin{array}{c}\text { Grits } \\
(\mathbf{g})\end{array}$ & $\begin{array}{c}\text { Ácido nítrico } \\
\mathbf{a} \mathbf{6 5 \%}(\mathbf{m L})\end{array}$ & $\begin{array}{c}\text { Ácido } \\
\text { clorídrico (mL) }\end{array}$ & $\begin{array}{c}\text { Peróxido de hidrogênio } \\
\mathbf{a ~ 3 0 \%}(\mathbf{m L})\end{array}$ \\
\hline $\mathbf{1}$ & 0,2539 & 4 & 2 & 2 \\
$\mathbf{2}$ & 0,2518 & 4 & 2 & 2 \\
$\mathbf{3}$ & 0,2508 & 4 & 2 & 2 \\
$\mathbf{4}$ & 0,2503 & 4 & 2 & 2 \\
$\mathbf{5}$ & 0,0000 & 4 & 2 & 2 \\
\hline
\end{tabular}


Para a realização do ensaio de lixiviação do solocimento com adição de grits é necessária a identificação dos possíveis elementos que o compõem. Sabendo-se da possibilidade de se encontrarem outros elementos químicos na mistura solo-cimento-grits que não foram detectados na análise química do resíduo, foram acrescentados outros elementos que constam no Anexo $\mathrm{F}$ da NBR 10004 (ABNT, 2004a) para realização do ensaio de lixiviação, a saber: arsênio (As), bário $(\mathrm{Ba})$, cromo total $(\mathrm{Cr})$ e selênio $(\mathrm{Se})$

Primeiramente, o solo-cimento com adição de grits foi triturado de modo a passar na peneira de 9,5 $\mathrm{mm}$. Logo após, foram pesadas três amostras de aproximadamente $50 \mathrm{~g}$ cada e transferidas para os frascos de lixiviação; um frasco foi mantido vazio. A amostra que não continha solo-cimento com adição de grits foi denominada "amostra branca", que teve a finalidade de avaliar a interferência dos reagentes utilizados em cada tubo em relação aos compostos que se quis determinar.

Em seguida, foi determinada a solução de extração, em função do $\mathrm{pH}$ da amostra. Medido o pH da amostra, passou-se à determinação da solução extratora da seguinte maneira: para $\mathrm{pH}$ menor ou igual a 5, deve-se utilizar a solução extratora número 1; e para $\mathrm{pH}$ maior do que 5 , deve-se adicionar $3,5 \mathrm{~mL}$ de $\mathrm{HCl} 1 \mathrm{~N}$, homogeneizar a solução, cobrir com vidro de relógio e aquecer a $50{ }^{\circ} \mathrm{C}$ durante $10 \mathrm{~min}$. Em seguida, deve-se esfriar a solução e medir o pH. Se o pH for menor ou igual a 5, deve-se utilizar a solução extratora número 1 , e se for maior do que 5, a solução extratora número 2. Para o grits triturado, o primeiro valor de $\mathrm{pH}$ foi maior do que 5 , tendo sido adotada a recomendação normativa, e a segunda medição de $\mathrm{pH}$ foi maior do que 5, sendo, portanto, utilizada a solução extratora número 2 .

Posteriormente, foram acrescentados $1.000 \mathrm{~g}$ da solução extratora (20 vezes a massa de grits triturada) a cada frasco, que, devidamente fechado, foi mantido sob agitação durante $(18 \pm 2) \mathrm{h}$ à temperatura de até $25{ }^{\circ} \mathrm{C}$, com uma rotação de $(30 \pm 2)$ rpm no agitador rotatório. Após esse período, as amostras foram filtradas e levadas ao espectrômetro de absorção atômica para proceder à leitura dos metais.

$\mathrm{O}$ valor do teor $(\mathrm{T})$ de cada metal encontrado em cada amostra, expresso em $\mu \mathrm{g} / \mathrm{g}$, foi obtido pela Equação 4:

$T(\mu g / g)=\frac{F_{d} V_{0}\left(L_{a}+L_{b}\right)}{M}$

Eq. 4

Onde:

$F_{d}$ : fator de diluição;
$V_{0}$ : volume da amostra;

$L_{a}+L_{b}$ : leitura dos metais; e

$M$ : massa da amostra.

$\mathrm{O}$ valor do teor médio $\left(\mathrm{T}_{\mathrm{m}}\right)$ de cada metal, expresso em $\mu \mathrm{g} / \mathrm{g}$, foi obtido pela Equação 5:

$T_{m}=\frac{T_{1}+T_{2}+T_{3}}{3}-T_{4}$

Onde:

$T_{1}$ : teor do metal encontrado na amostra 1 ;

$T_{2}$ : teor do metal encontrado na amostra 2;

$T_{3}$ : teor do metal encontrado na amostra 3; e

$T_{4}$ : teor do metal encontrado na amostra 4 (amostra branca).

\section{Solubilização do solo-cimento com adição de grits}

Novamente para o traço ótimo, foi realizado o ensaio de solubilização, conforme os procedimentos da NBR 10006 (ABNT, 2004c).

Para a realização do ensaio de solubilização do solo-cimento com adição de grits é necessária a identificação dos possíveis elementos que o compõem. Sabendo-se da possibilidade de se encontrarem outros elementos químicos na mistura solo-cimento-grits que não foram detectados na análise química do resíduo, foram acrescentados alguns elementos que constam no Anexo $G$ da NBR 10004 (ABNT, 2004a) para realização do ensaio de lixiviação, sendo eles arsênio (As), bário $(\mathrm{Ba})$, cromo total $(\mathrm{Cr})$ e selênio $(\mathrm{Se})$.

Primeiramente, o solo-cimento com adição de grits foi triturado para se obter uma granulometria que passasse na peneira de 9,5 $\mathrm{mm}$. Logo após, foram pesadas duas amostras secas de aproximadamente $250 \mathrm{~g}$ cada e transferidas para frascos de 1.500 $\mathrm{mL}$. Um frasco foi mantido vazio. A amostra que não continha solo-cimento com adição de grits é denominada amostra branca, que teve a finalidade de avaliar a interferência dos reagentes utilizados em cada tubo em relação aos compostos que se quis determinar.

Posteriormente, adicionaram-se $1.000 \mathrm{~mL}$ de água destilada e deionizada e agitou-se a amostra em baixa velocidade por $5 \mathrm{~min}$. $\mathrm{O}$ frasco foi coberto com filme de PVC e deixado em repouso por 7 dias em temperatura até $25^{\circ} \mathrm{C}$. A solução foi filtrada e levada ao espectrômetro de absorção atômica para proceder à leitura dos metais.

$\mathrm{O}$ valor do teor $(\mathrm{T})$ de cada metal encontrado em cada amostra, expresso em $\mu \mathrm{g} / \mathrm{g}$, foi obtido pela Equação 6:

36 Pinheiro, M. L.; Alvarenga, R. de C. S.; Ribeiro, B. C.; Silva Júnior, P. R.; Sarmet, M. S.; Fassoni, D. P. 
$T(\mu g / g)=\frac{F_{d} V_{0}\left(L_{a}+L_{b}\right)}{M}$

Eq. 6

Onde:

$F_{d}$ : fator de diluição;

$V_{0}$ : volume da amostra;

$L_{a}+L_{b}$ : leitura dos metais; e

$M$ : massa da amostra.

$\mathrm{O}$ valor do teor médio $\left(\mathrm{T}_{\mathrm{m}}\right)$ de cada metal, expresso em $\mu \mathrm{g} / \mathrm{g}$, foi obtido pela Equação 7:

$T_{m}=\frac{T_{1}+T_{2}}{2}-T_{3}$

Eq. 7

Onde:

$T_{1}$ : teor do metal encontrado na amostra 1 ;

$T_{2}$ : teor do metal encontrado na amostra 2; e

$T_{3}$ : teor do metal encontrado na amostra 3 (amostra branca).

\section{Resultados e discussão}

\section{Análise granulométrica}

O solo utilizado apresentou massa específica dos sólidos igual a $2,75 \mathrm{~g} / \mathrm{cm}^{3}$, percentual passante na peneira de abertura de malha $4,8 \mathrm{~mm}$ de $100 \%$, e na peneira de abertura de malha $0,075 \mathrm{~mm}$ de $13,17 \%$. A curva granulométrica do solo pode ser observada na Figura 3.

O grits utilizado apresentou massa específica dos sólidos igual a $2,76 \mathrm{~g} / \mathrm{cm}^{3}$, percentual passante na peneira de abertura de malha $4,8 \mathrm{~mm}$ de $100 \%$, e na peneira de abertura de malha $0,075 \mathrm{~mm}$ de $26,78 \%$. A curva granulométrica do grits pode ser observada na Figura 4.

Em relação à distribuição granulométrica do solo e do grits, pode-se observar nas Figuras 3 e 4 respectivamente que ambos atendem aos requisitos da NBR 10832 (ABNT, 1989), uma vez que para os dois materiais têm-se $100 \%$ passante na peneira de abertura de malha $4,8 \mathrm{~mm}$ e $10 \%$ a $50 \%$ passante na peneira de abertura de malha 0,075 mm. Assim, conclui-se que todos os teores de solo-grits também atenderão aos requisitos estabelecidos pela norma.

\section{Determinação do limite de liquidez}

Os resultados obtidos no ensaio de limite de liquidez (LL) para os diversos teores de solo-grits em massa podem ser observados na Figura 5.

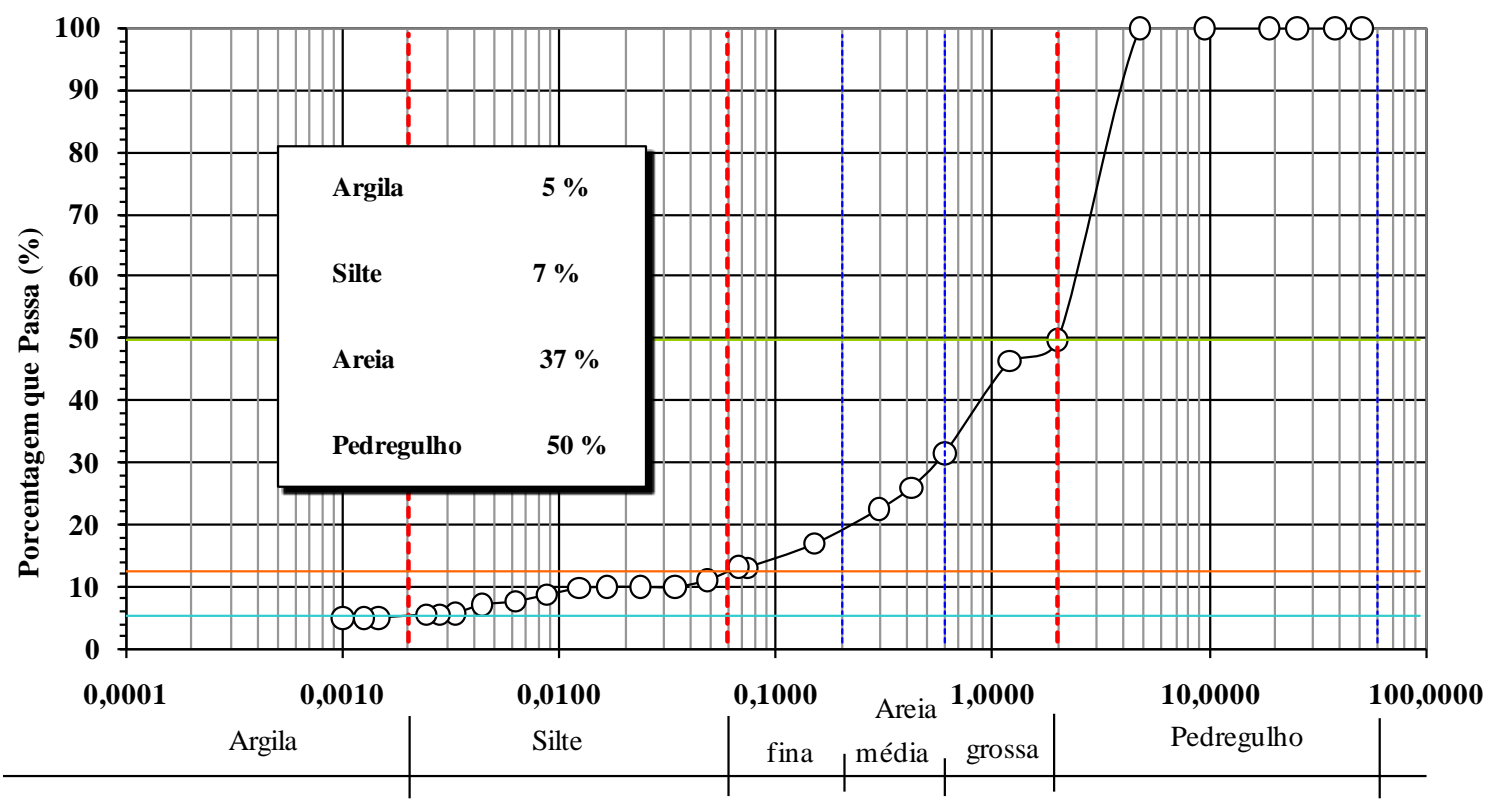

Diâmetro da Partícula (mm)

Figura 3 - Curva granulométrica do solo 


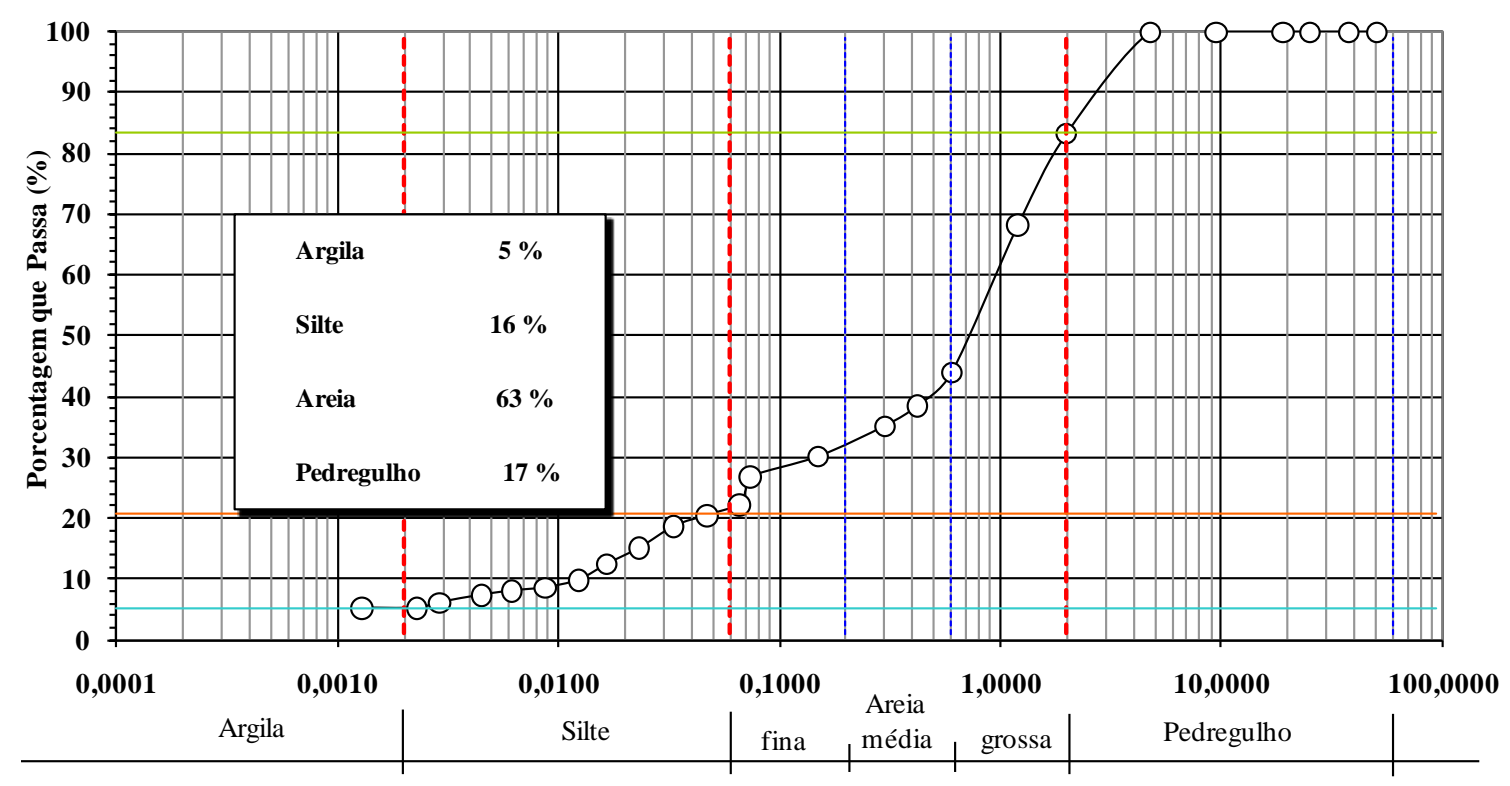

Diâmetro da Partícula (mm)

Figura 4 - Curva granulométrica do grits

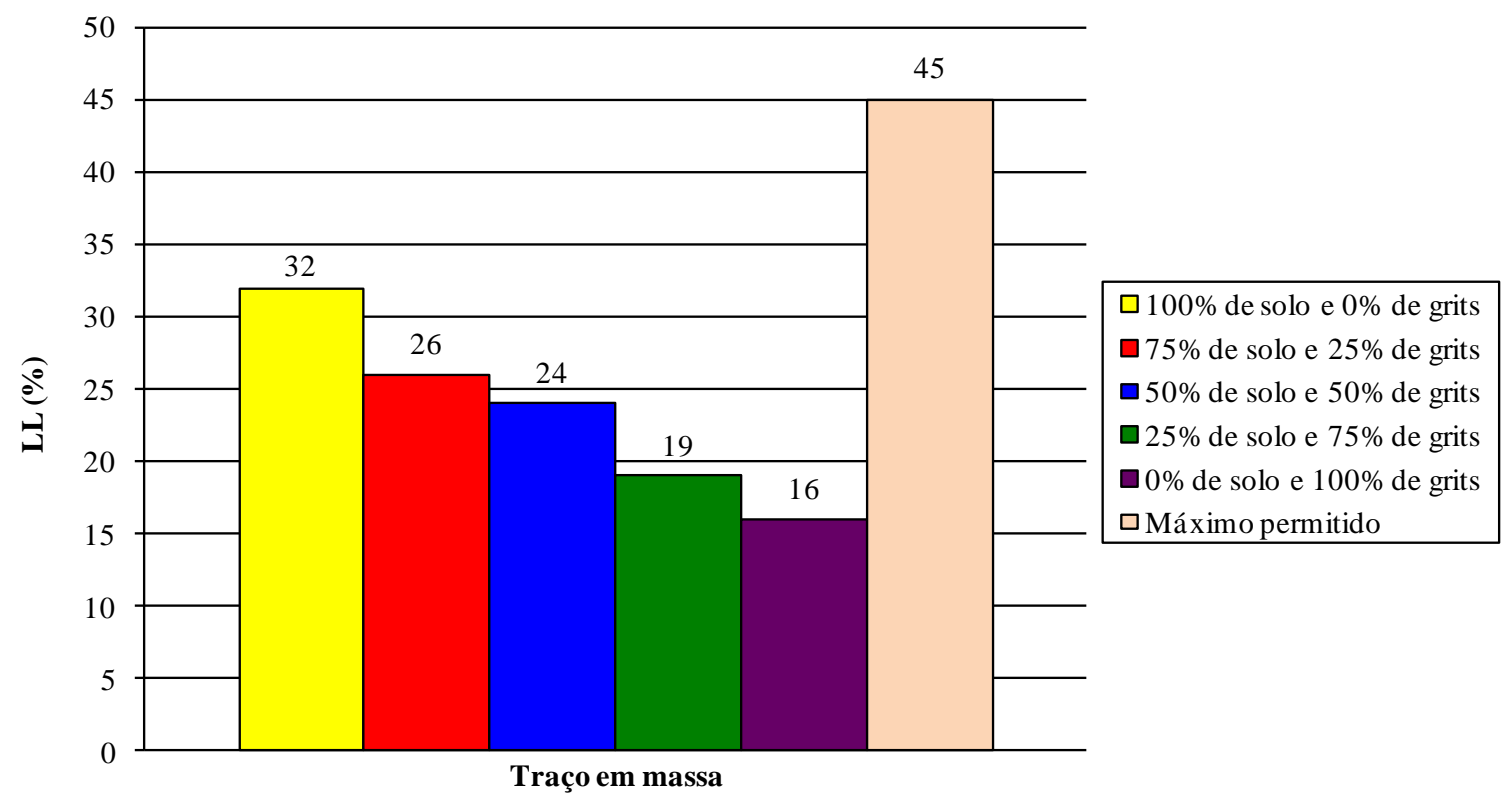

Figura 5 - Resultados dos ensaios de limite de liquidez (LL) para os diversos teores de solo-grits e comparação com o limite permitido pela NBR 10832 (ABNT, 1989)

Nota-se na Figura 5 que, com o aumento do teor de grits, houve redução do LL, já que o grits apresenta características arenosas. Além disso, todos os teores de solo-grits analisados atendem ao requisito da NBR 10832 (ABNT, 1989) em relação ao limite de liquidez, sendo inferiores ao máximo permitido de $45 \%$.

\section{Determinação do limite de plasticidade e índice de plasticidade}

Os resultados obtidos no ensaio de limite de plasticidade (LP) podem ser observados na Figura 6, para os diversos teores de solo-grits em massa, correspondentes às porcentagens de 100-0, 75-25, 50-50, 25-75 e 0-100.

Os valores obtidos para o índice de plasticidade (IP) podem ser observados na Figura 7, para os diversos teores de solo-grits em massa. 


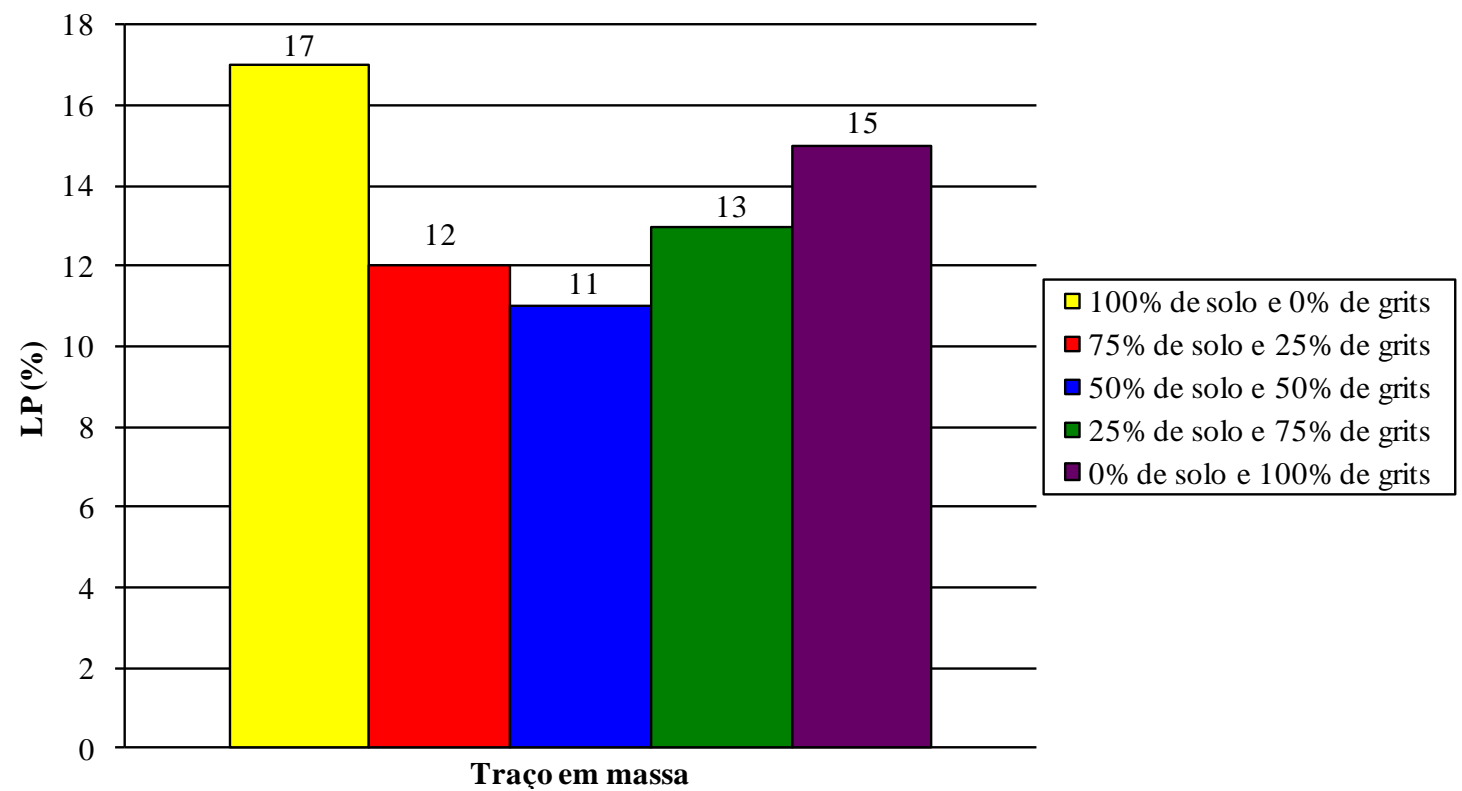

Figura 6 - Resultados dos ensaios de limite de plasticidade (LP) para os diversos teores de solo-grits

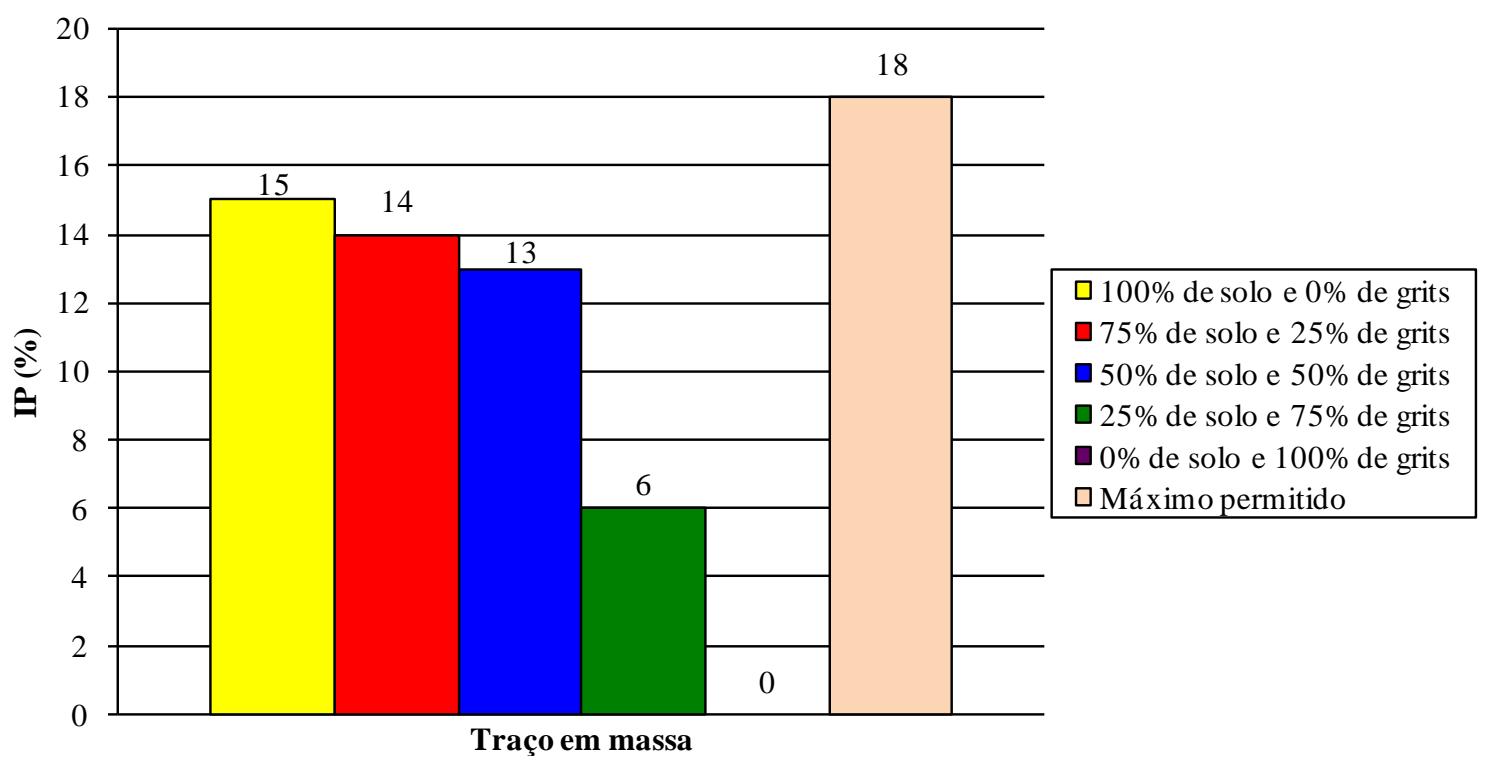

Figura 7 - Valores obtidos para o índice de plasticidade (IP) para os diversos teores de solo-grits e comparação com o limite permitido pela NBR 10832 (ABNT, 1989)

Pode-se perceber na Figura 6 que não houve grandes variações nos valores do LP com o aumento do teor de grits. Observa-se na Figura 7 que, com o aumento do teor de grits, houve redução do IP. Este fato se deve à redução ocorrida no LL, tendo em vista que o LP pouco se alterou com o aumento do teor de grits. Todos os teores de solo-grits obtidos atendem ao requisito da NBR 10832 (ABNT, 1989) em relação ao índice de plasticidade, com valores inferiores ao máximo permitido, de $18 \%$.

\section{Ensaio prático da caixa}

Os resultados obtidos no ensaio prático da caixa para os teores de solo-grits em massa correspondentes às porcentagens 100-0, 75-25 e 50-50 podem ser observados na Figura 8. Apenas esses teores foram considerados, pois, como se pode perceber, com o aumento do teor de grits, houve redução da retração. Isso se deve ao fato de a mistura se tornar mais arenosa com o aumento do teor de grits. Foi também possível perceber que não apareceram trincas nas amostras após o período de 7 dias. 
Em relação ao ensaio prático da caixa, pode-se notar na Figura 8 que todos os teores de solo-grits obtidos atendem às prescrições deste ensaio sugeridas pelo Ceped (CENTRO..., 1978), com retração menor ou igual a $2 \mathrm{~cm}$ e ausência de trincas nas amostras.

\section{Ensaio de compactação}

Os resultados obtidos no ensaio de compactação, umidade ótima e massa específica seca máxima para os teores de solo-grits em massa correspondentes às porcentagens 100-0, 75-25 e $50-50$ respectivamente podem ser observados nas Figuras 9 e 10.
Analisando os resultados dos ensaios de compactação apresentados nas Figuras 9 e 10, percebe-se que o aumento do teor de grits conduz a uma redução da umidade ótima e a um aumento do peso específico seco máximo.

\section{Resistência à compressão}

Para o traço-base em massa de 1:10 de cimento e solo, os resultados obtidos para a resistência à compressão média dos corpos de prova aos 13 dias, para os diversos teores de solo-grits, em massa, correspondentes às porcentagens 100-0, 7525 e 50-50, podem ser observados na Figura 11.

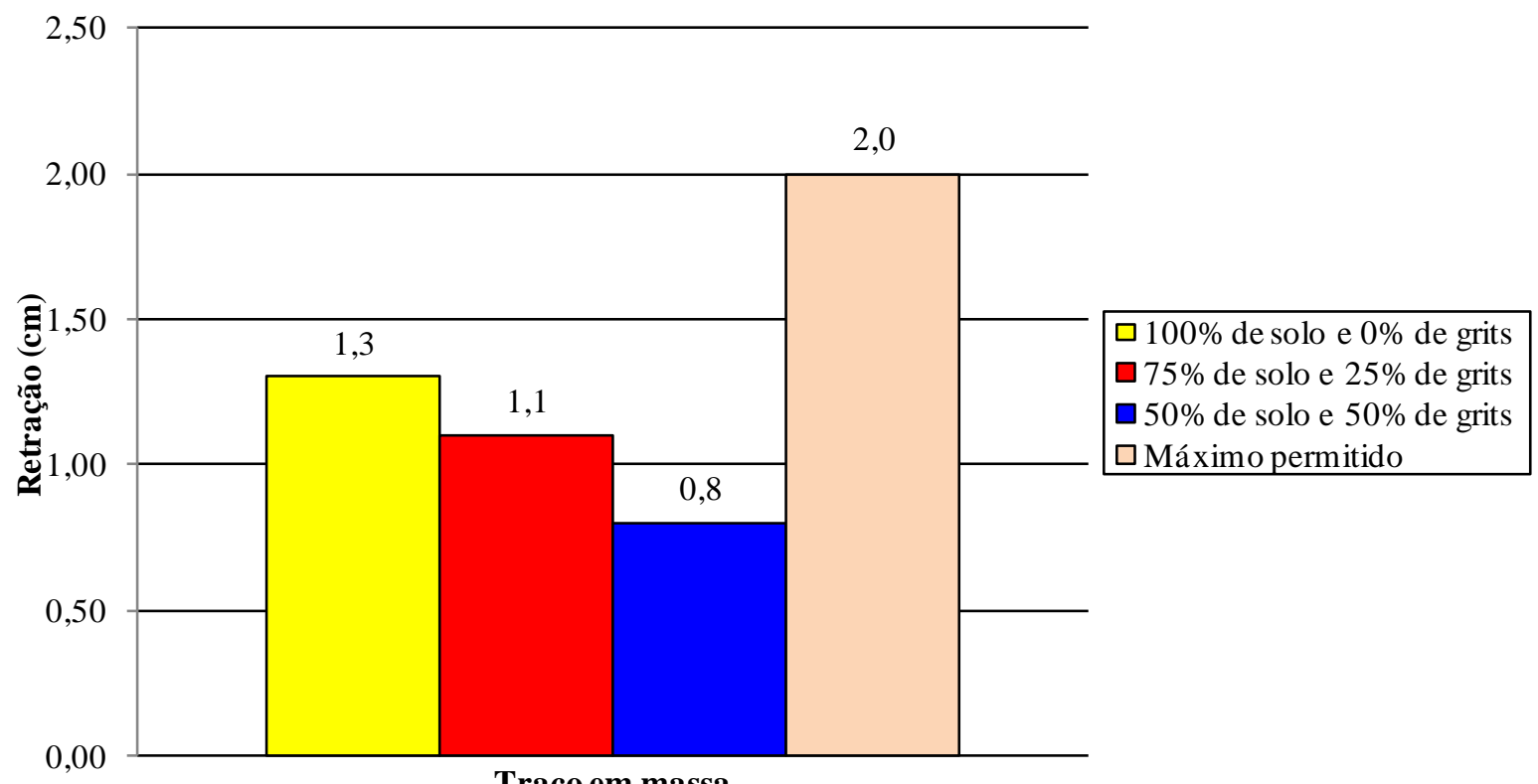

Traço em massa

Figura 8 - Resultados dos ensaios práticos da caixa para os diversos teores de solo-grits e comparação com o limite permitido

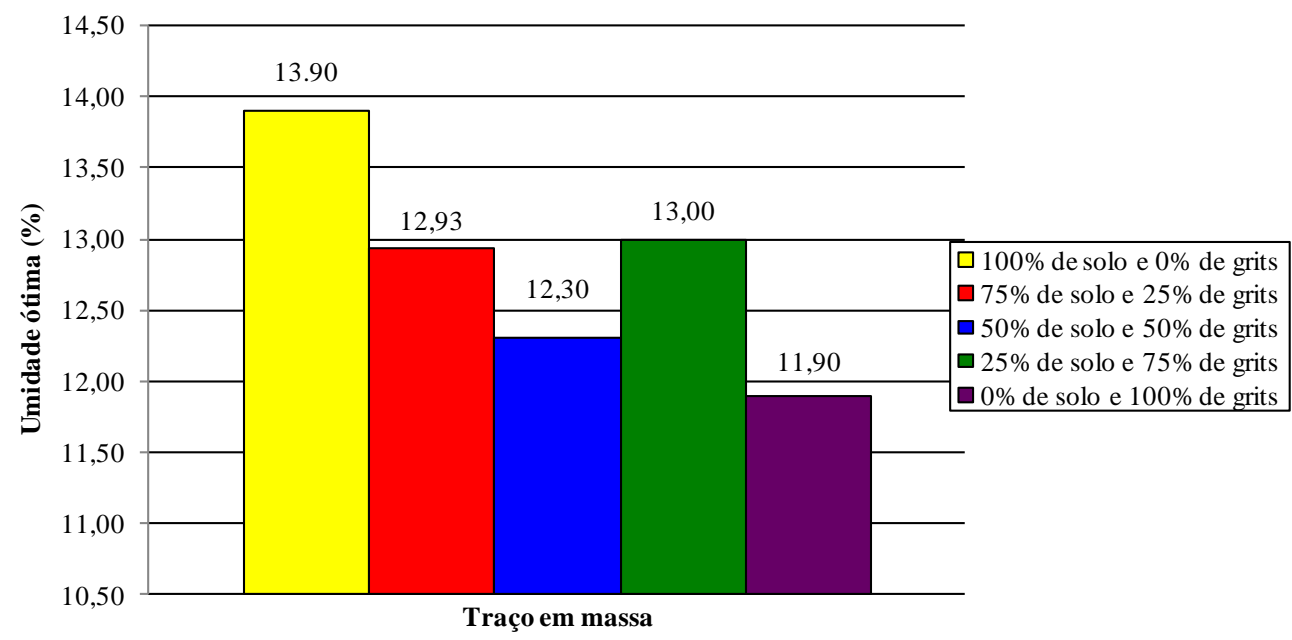

Figura 9 - Valores obtidos para a umidade ótima para os diversos teores de solo-grits

40 Pinheiro, M. L.; Alvarenga, R. de C. S.; Ribeiro, B. C.; Silva Júnior, P. R.; Sarmet, M. S.; Fassoni, D. P. 


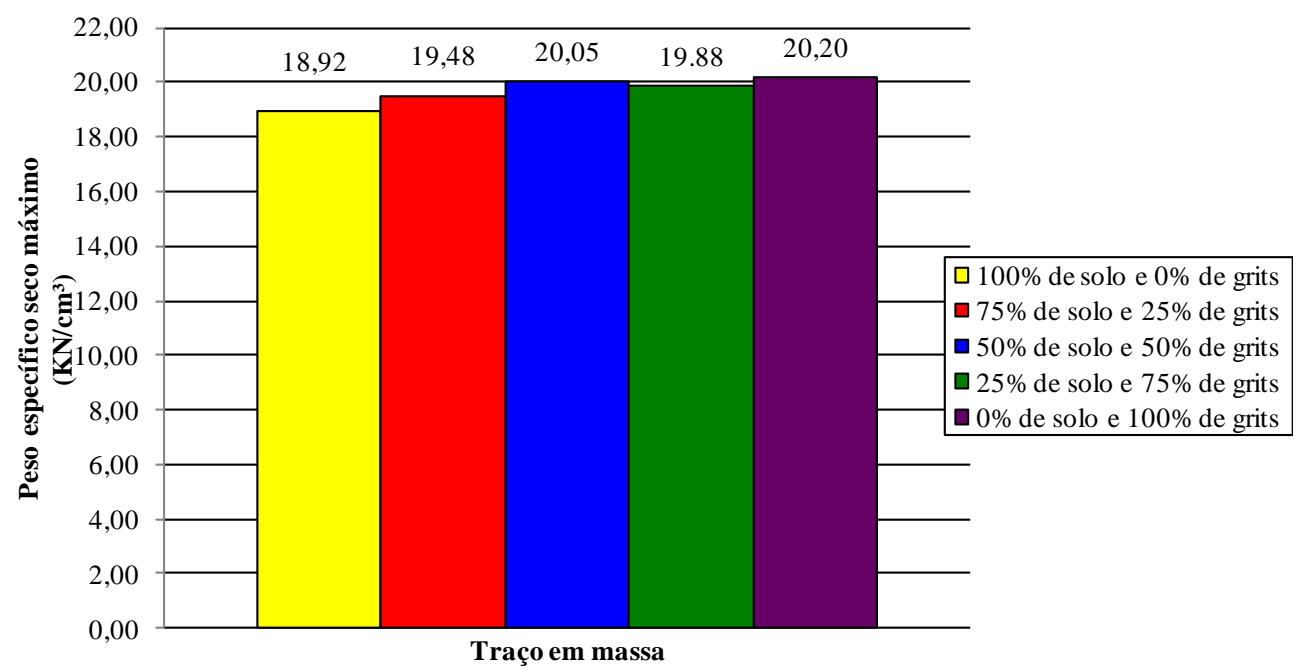

Figura 10 - Valores obtidos para a massa específica seca máxima para os diversos teores de solo-grits

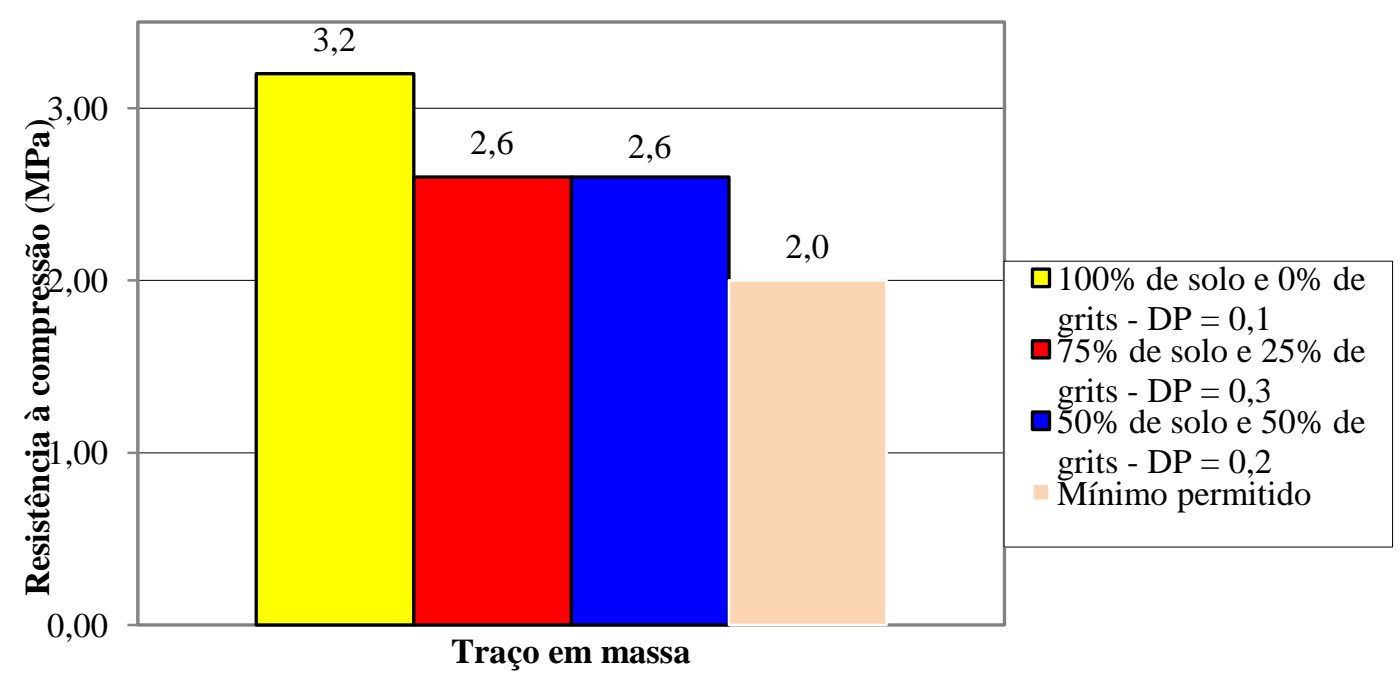

Figura 11 - Resultados para a resistência à compressão média dos corpos de prova e o desvio padrão (DP), aos 13 dias, para os diversos teores de solo-grits, a partir do traço-base em massa de 1:10, de cimento e solo, e comparação com o limite permitido da NBR 10836 (ABNT, 1994b)

Nota-se na Figura 12 que a porcentagem de sologrits, em massa, respectivamente 37,5 e 67,5, atende ao requisito da NBR 10836 (ABNT, 1994b) em relação à resistência à compressão, já que o valor médio de resistência à compressão aos 28 dias de idade dos corpos de prova desse teor de solo-grits foi superior ao mínimo permitido, de 2,0 $\mathrm{MPa}$.

\section{Absorção de água}

Para o traço-base em massa de 1:10, cimento e solo respectivamente, os resultados obtidos para a absorção de água média dos corpos de prova aos
28 dias, para os diversos teores de solo-grits, podem ser observados na Figura 13.

Pode-se notar na Figura 13 que todas as porcentagens de solo-grits, em massa, 100-0, 7525 e 50-50, atenderam ao requisito da NBR 10836 (ABNT, 1994b) em relação à absorção de água, já que todos os valores médios foram inferiores ao máximo permitido, de $20 \%$.

Para o traço-base em massa de 1:10, de cimento e solo respectivamente, o resultado obtido para a absorção de água média dos corpos de prova, aos 28 dias, para o teor de solo-grits, em massa, correspondente às porcentagens, respectivamente, de 37,5 e 62,5, pode ser observado na Figura 14. 


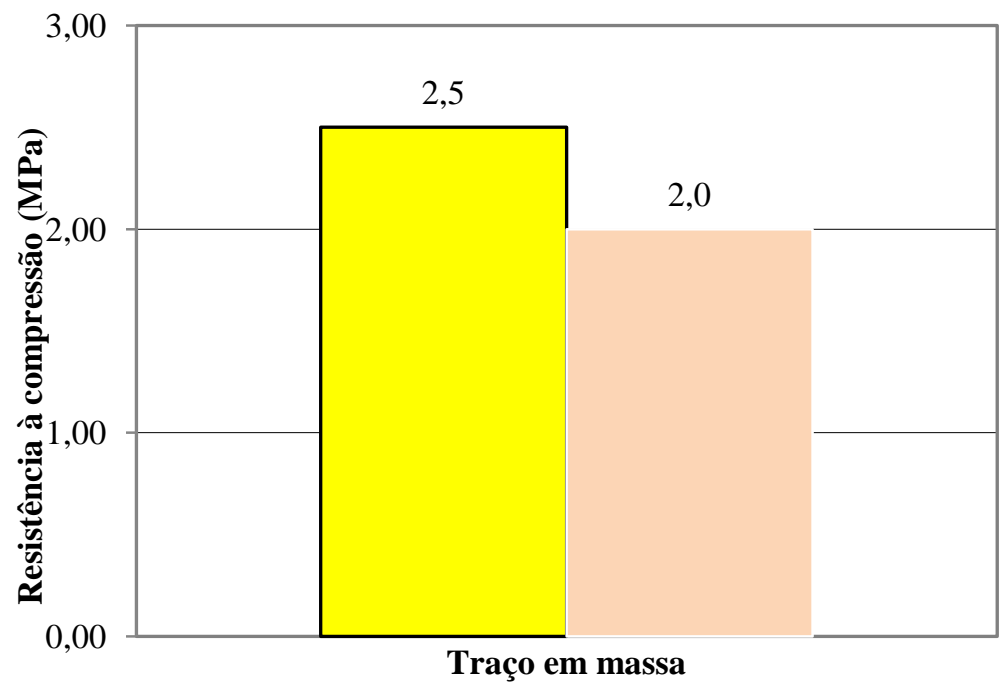

$\square 37,5 \%$ de solo e $62,5 \%$ de grits - DP $=0,1$

Mínimo permitido

Figura 12 - Resultados do ensaio de resistência à compressão média dos corpos de prova e o desvio padrão (DP), aos 28 dias, para o teor de $37,5 \%$ de solo e $62,5 \%$ de grits, em massa, a partir do traçobase em massa de 1:10, de cimento e solo, respectivamente, e comparação com o limite permitido NBR 10836 (ABNT, 1994b)

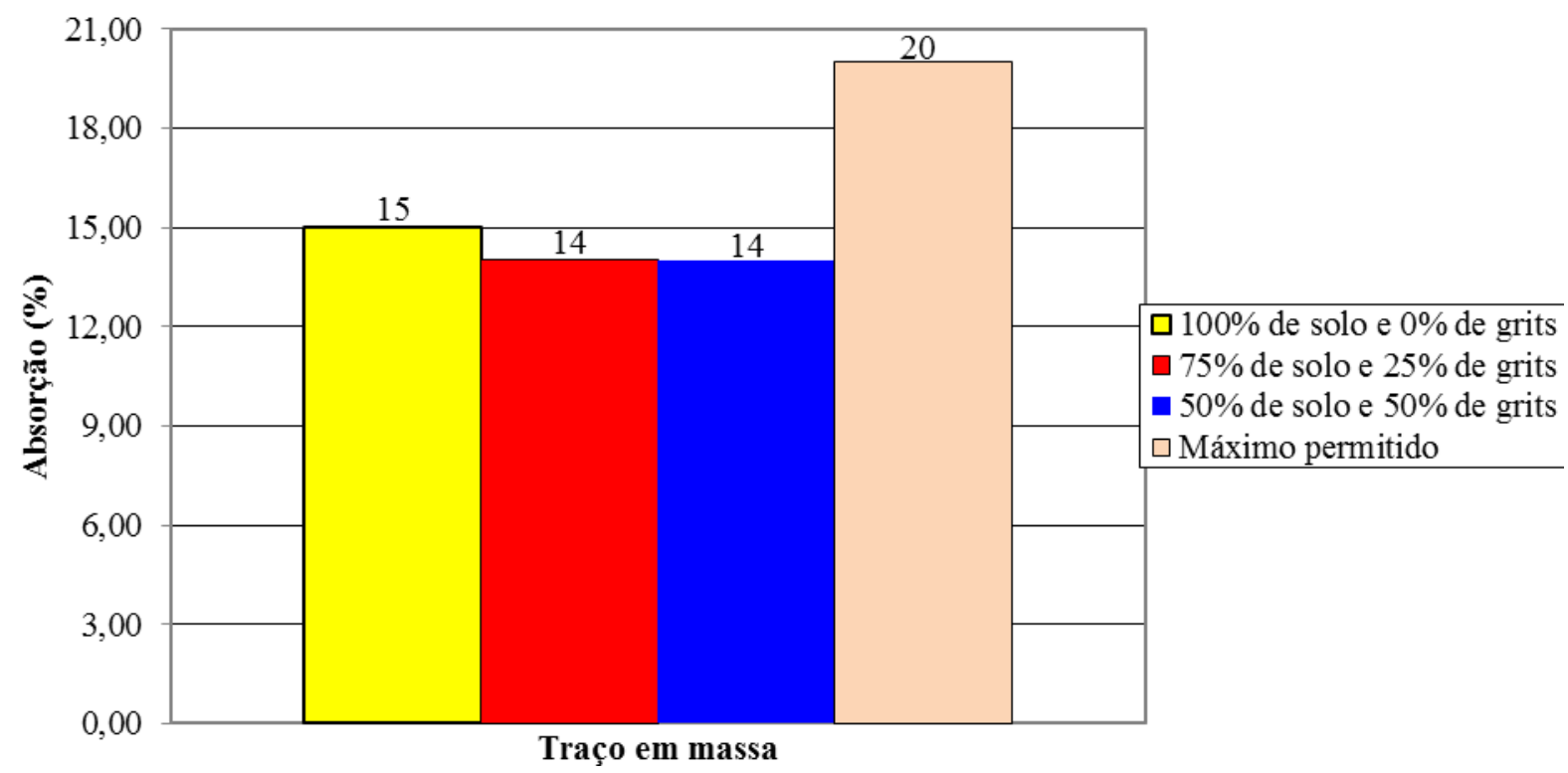

Figura 13 - Resultados para a absorção de água média dos corpos de prova, aos 28 dias, para os diversos teores de solo-grits, a partir do traço-base em massa de 1:10, de cimento e solo respectivamente, e comparação com o limite permitido da NBR 10836 (ABNT, 1994b)

Percebe-se na Figura 14 que todos os corpos de prova correspondentes às porcentagens de sologrits de 37,5 e 67,5 atendem ao requisito da NBR 10836 (ABNT, 1994b) em relação à absorção de água, uma vez que apresentaram valores individuais de absorção de água aos 28 dias de idade inferiores ao máximo permitido, de $22 \%$.

\section{Análise química do grits}

Com base na revisão bibliográfica foram determinados os metais do grits que foram procurados durante a leitura por espectrofotometria por absorção atômica. Os metais encontrados e seus respectivos teores podem ser observados na Tabela 2.

42 Pinheiro, M. L.; Alvarenga, R. de C. S.; Ribeiro, B. C.; Silva Júnior, P. R.; Sarmet, M. S.; Fassoni, D. P. 


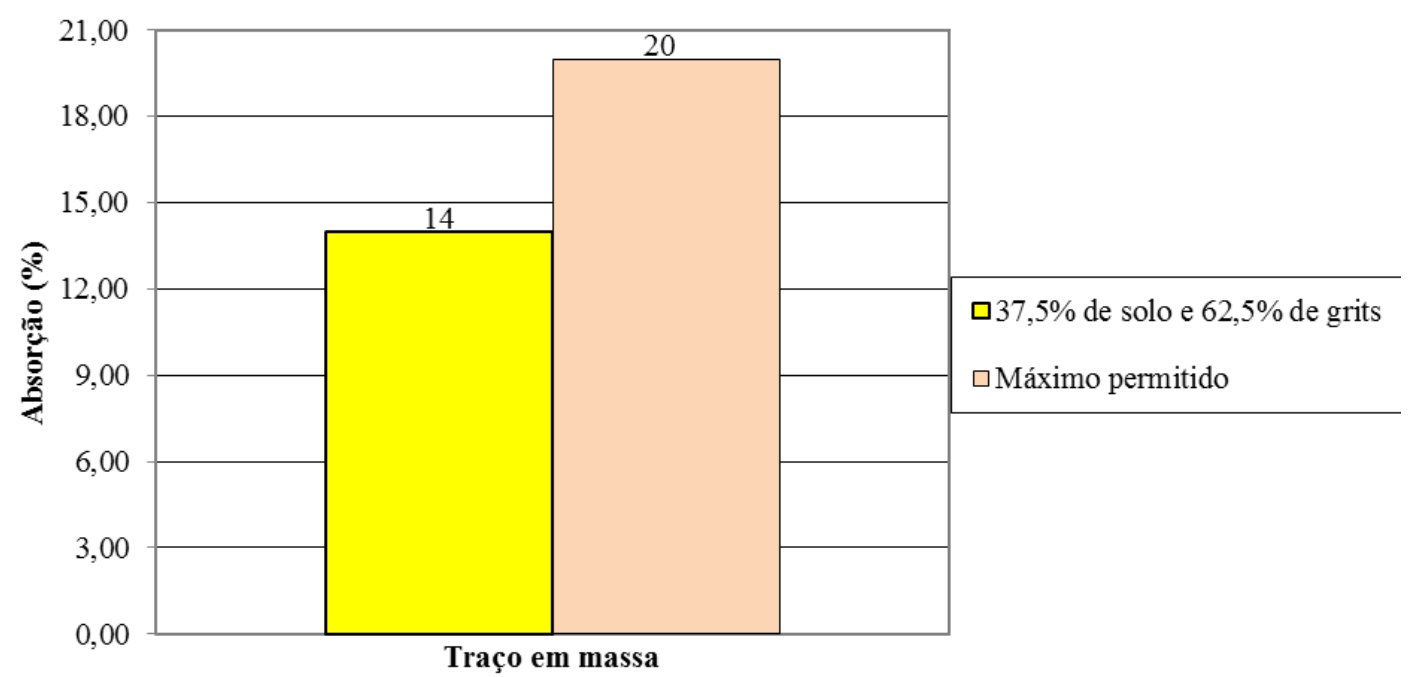

Figura 14 - Resultados para a absorção de água média dos corpos de prova, aos 28 dias, para o teor de $37,5 \%$ de solo e $62,5 \%$ de grits, em massa, a partir do traço-base em massa de $1: 10$, de cimento e solo respectivamente, e comparação com o limite permitido pela NBR 10836 (ABNT, 1994b)

Tabela 2 - Metais encontrados no grits e seus respectivos teores

\begin{tabular}{c|r|r}
\hline \multirow{2}{*}{ Elemento } & \multicolumn{2}{|c}{ Teor } \\
\cline { 2 - 3 } & \multicolumn{1}{|c}{$(\boldsymbol{\mu g} / \mathbf{g})$} & \multicolumn{1}{c}{$(\mathbf{\%})$} \\
\hline $\mathbf{C u}$ & 0,54 & 0,000054 \\
$\mathbf{C d}$ & 11,30 & 0,001130 \\
$\mathbf{N i}$ & 14,34 & 0,001434 \\
$\mathbf{M n}$ & 68,88 & 0,006888 \\
$\mathbf{P b}$ & 70,41 & 0,007041 \\
$\mathbf{M g}$ & 87,08 & 0,008708 \\
$\mathbf{Z n}$ & 118,07 & 0,011807 \\
$\mathbf{F e}$ & 637,49 & 0,063749 \\
$\mathbf{C a}$ & 26150,00 & 2,615000 \\
$\mathbf{N a}$ & 671000,00 & 67,100000 \\
\hline
\end{tabular}

\section{Lixiviação do solo-cimento com adição de grits}

Com base na análise química e no Anexo $\mathrm{F}$ da NBR 10004 (ABNT, 2004a) foram determinados os metais do extrato lixiviado da mistura solocimento-grits (teor de solo-grits, em massa, correspondente às porcentagens, respectivamente, de 37,5 e 62,5 , a partir do traço-base em massa de $1: 10$, de cimento e solo respectivamente) que foram procurados durante a leitura por espectrofotometria por absorção atômica. Os metais encontrados e seus respectivos teores podem ser observados na Tabela 3 .

Percebe-se na Tabela 3 que o extrato lixiviado do solo-cimento com adição de grits atende aos requisitos da NBR 10005 (ABNT, 2004b) em relação à toxidade, uma vez que todos os teores dos elementos encontrados apresentaram valores inferiores aos máximos permitidos. Portanto, o solo-cimento com adição de grits é caracterizado como não tóxico, podendo ser utilizado sem restrição.

\section{Solubilização do solo-cimento com adição de grits}

Com base na análise química e no Anexo G da NBR 10004 (ABNT, 2004a) foram determinados os metais do extrato solubilizado do solo-cimento com adição de grits (teor de solo-grits, em massa, correspondente às porcentagens, respectivamente, de 37,5 e 62,5 , a partir do traço-base em massa de 1:10, de cimento e solo respectivamente) que foram procurados durante a leitura por espectrofotometria por absorção atômica. Os metais encontrados e seus respectivos teores podem ser observados na Tabela 4. 
Tabela 3 - Metais encontrados no extrato lixiviado, seus respectivos teores e comparação com o limite permitido pela NBR 10004 (ABNT, 2004a)

\begin{tabular}{c|c|c}
\hline Elemento & $\begin{array}{c}\text { Teor encontrado } \\
(\mu \mathrm{g} / \mathrm{g})\end{array}$ & $\begin{array}{c}\text { Teor máximo permitido } \\
(\mu \mathrm{g} / \mathrm{g})\end{array}$ \\
\hline $\mathbf{C u}$ & 0,00 & - \\
$\mathbf{C d}$ & 0,00 & 0,5 \\
$\mathbf{N i}$ & 1,08 & - \\
$\mathbf{M n}$ & 25,85 & - \\
$\mathbf{P b}$ & 0,38 & 1,0 \\
$\mathbf{M g}$ & 882,65 & - \\
$\mathbf{Z n}$ & 0,00 & - \\
$\mathbf{F e}$ & 0,00 & - \\
$\mathbf{C a}$ & 40061,60 & - \\
$\mathbf{N a}$ & 4533,36 & - \\
$\mathbf{A s}$ & 0,00 & 1,0 \\
$\mathbf{B a}$ & 5,78 & 70,0 \\
$\mathbf{C r}$ & 2,17 & 5,0 \\
$\mathbf{S e}$ & 0,00 & 1,0 \\
\hline
\end{tabular}

Nota: teor de $37,5 \%$ de solo e de $62,5 \%$ de grits, em massa, a partir do traço-base em massa de 1:10, de cimento e solo respectivamente.

Tabela 4 - Metais encontrados no extrato solubilizado, seus respectivos teores e comparação com o limite permitido pela NBR 10004 (ABNT, 2004a)

\begin{tabular}{c|c|c}
\hline \multirow{2}{*}{ Elemento } & Teor encontrado & Teor máximo permitido \\
\cline { 2 - 3 } & $(\boldsymbol{\mu g} / \mathbf{g})$ & $(\mu \mathrm{g} / \mathbf{g})$ \\
\hline $\mathbf{C u}$ & 0,08 & 2,0 \\
$\mathbf{C d}$ & 0,004 & 0,005 \\
$\mathbf{N i}$ & 0,05 & - \\
$\mathbf{M n}$ & 0,05 & 0,1 \\
$\mathbf{P b}$ & 0,321 & 0,01 \\
$\mathbf{M g}$ & 0,00 & - \\
$\mathbf{Z n}$ & 0,07 & 5,0 \\
$\mathbf{F e}$ & 1,09 & 0,3 \\
$\mathbf{C a}$ & 49,14 & - \\
$\mathbf{N a}$ & 3192,06 & 200,0 \\
$\mathbf{A s}$ & 0,000 & 0,01 \\
$\mathbf{B a}$ & 0,07 & 0,7 \\
$\mathbf{C r}$ & 2,214 & 0,05 \\
$\mathbf{S e}$ & 0,000 & 0,01 \\
\hline
\end{tabular}

Nota: teor de $37,5 \%$ de solo e $62,5 \%$ de grits, em massa, a partir do traço-base em massa de $1: 10$, de cimento e solo respectivamente.

Percebe-se na Tabela 4 que o extrato solubilizado do solo-cimento com adição de grits não atende aos requisitos da NBR 10005 (ABNT, 2004b) em relação ao padrão de potabilidade da água, uma vez os teores de $\mathrm{Pb}, \mathrm{Fe}, \mathrm{Na}$ e $\mathrm{Cr}$ apresentaram valores superiores aos máximos permitidos. Portanto, o solo-cimento com adição de grits possui constituintes que são solubilizados em concentrações superiores ao permitido.

\section{Considerações finais}

Em relação à caracterização física, pode-se concluir que todos os teores de solo-grits, em massa, correspondentes às porcentagens 100-0, 7525, 50-50, 25-75 e 0-100, atenderam às exigências da NBR 10832 (ABNT, 1989). Logo, era de se esperar que fosse possível produzir blocos prensados de encaixe de solo-cimento com todos eles. No entanto, na prática, sabe-se que, para que seja possível retirar o bloco da prensa e removê-lo para o local de cura, é necessário um mínimo de plasticidade da mistura. Dessa forma, foi possível fabricar blocos apenas com as seguintes porcentagens de solo-grits, em massa: 100-0, 7525 e 50-50.

Quanto à resistência à compressão e absorção de água, pode-se concluir que todos os teores de solo-

44 Pinheiro, M. L.; Alvarenga, R. de C. S.; Ribeiro, B. C.; Silva Júnior, P. R.; Sarmet, M. S.; Fassoni, D. P. 
grits, em massa, correspondentes às porcentagens 100-0, 75-25 e 50-50, atendem às exigências da NBR 10836 (ABNT, 1994b).

Dessa forma, pretendendo-se verificar a maior quantidade de resíduo que poderia ser utilizada, respeitando-se as exigências normativas, foram fabricados blocos com um teor de solo-grits, em massa, respectivamente de $37,5 \%$ e $62,5 \%$, intermediário aos teores 50-50 e 25-75. Como não foi possível produzir blocos com o teor de sologrits, em massa, de 25-75, por não ter sido possível retirar os blocos da prensa, optou-se por esse teor intermediário.

Em relação à resistência à compressão e absorção de água, pode-se concluir que o teor de solo-grits, em massa, correspondente às porcentagens $37,5 \mathrm{e}$ 67,5 atendeu às exigências da NBR 10836 (ABNT, 1994b), sendo definido como o teor que utiliza a maior quantidade de resíduo e que tem a plasticidade mínima necessária para que seja possível fabricar blocos, retirá-los da prensa e removê-los para o local de cura, atendendo às exigências normativas.

O teor de solo-grits, em massa, correspondente às porcentagens 37,5 e 67,5 , não apresentou características de inflamabilidade, reatividade, toxicidade e patogenicidade, porém apresentou constituintes que são solubilizados em concentrações superiores ao permitido pela NBR 10004 (ABNT, 2004a), sendo classe II A. No entanto, esse fato não inviabiliza seu uso para o fim a que se propõe, devendo ser utilizado com as devidas precauções. Sugere-se a utilização de revestimento com pintura para evitar que os elementos solubilizados possam causar possível contaminação da água e/ou trazer consequências à saúde do homem.

Portanto, o uso do grits na produção de blocos de encaixe de solo-cimento surge como uma alternativa viável, além de minimizar a degradação ambiental, causada pelos aterros e uso de recursos naturais, como jazidas de solo.

\section{Referências}

ASSOCIAÇÃO BRASILEIRA DE NORMAS TÉCNICAS. NBR 10832: fabricação de tijolo maciço de solo-cimento com utilização de prensa manual. Rio de Janeiro, 1989.

ASSOCIAÇÃO BRASILEIRA DE NORMAS TÉCNICAS. NBR 10834: bloco vazado de solocimento sem função estrutural. Rio de Janeiro, 1994.

ASSOCIAÇÃO BRASILEIRA DE NORMAS

TÉCNICAS. NBR 7181: solo: análise

granulométrica. Rio de Janeiro, 1984a.
ASSOCIAÇÃO BRASILEIRA DE NORMAS TÉCNICAS. NBR 6459: solo: determinação do limite de liquidez. Rio de Janeiro, 1984b.

ASSOCIAÇÃO BRASILEIRA DE NORMAS TÉCNICAS. NBR 7180: solo: determinação do limite de plasticidade. Rio de Janeiro, 1984c.

\section{ASSOCIAÇÃO BRASILEIRA DE NORMAS}

TÉCNICAS. NBR 7182: solo: ensaio de

Compactação. Rio de Janeiro, 1984d.

ASSOCIAÇÃO BRASILEIRA DE NORMAS TÉCNICAS. NBR 10836: bloco vazado de solocimento sem função estrutural: determinação da resistência à compressão e da absorção de água. Rio de Janeiro, 1994b.

ASSOCIAÇÃO BRASILEIRA DE NORMAS TÉCNICAS. NBR 10004: resíduos sólidos: classificação. Rio de Janeiro, 2004a.

ASSOCIAÇÃO BRASILEIRA DE NORMAS TÉCNICAS. NBR 10005: procedimento para obtenção de extrato lixiviado de resíduos sólidos. Rio de Janeiro, 2004b.

ASSOCIAÇÃO BRASILEIRA DE NORMAS TÉCNICAS. NBR 10006: procedimento para obtenção de extrato solubilizado de resíduos sólidos. Rio de Janeiro, 2004c.

CENTRO DE PESQUISA E DESENVOLVIMENTO. Manual Prático de Construção em Solo-Cimento. Camaçari: BNH; Ceped, 1978.

MACHADO, C. C.; PEREIRA, R. S.; PIRES, J. M. M. Influência do Tratamento Térmico do Resíduo Sólido Industrial (grits) na Resistência Mecânica de Um Latossolo Para Pavimentos de Estradas Florestais. Revista Árvore, Viçosa, v. 27, n. 4, p. 543-550, jul./ago. 2003.

MACHADO, C. C. et al. Caracterização Tecnológica de Misturas Solo-Grits Para Pavimentos de Estradas Florestais: influência do tratamento térmico do grits na resistência mecânica das misturas. Revista Ârvore, Viçosa, v. 31, n. 3, p. 487-494, maio/jun. 2007.

MACHADO, C. C. et al. Comportamento Geotécnico de Misturas Granulométricas de SoloGrits. Revista Árvore, Viçosa, v. 33, n. 3, p. 555562, maio/jun. 2009.

PEREIRA, R. S.; MACHADO, C. C.;

CARVALHO, C. A. B. Aplicação de Misturas

Solo-Grits em Estradas Florestais: resistência mecânica via CBR. Revista Árvore, Viçosa, v. 30, n. 4, p. 619-627, jul./ago. 2006.

PETRUCCI, E. G. R. Concreto de Cimento Portland. 13. ed. São Paulo: Globo, 1998. 
RIBEIRO, A. P. Avaliação do Uso de Resíduos Sólidos Inorgânicos da Produção de Celulose em Materiais Cerâmicos. 149 f. São Paulo, 2010. Tese (Doutorado em Engenharia de Materiais e Metalúrgica) - Escola de Engenharia, Universidade Federal de São Paulo, São Paulo, 2010.
SOUZA, T. I.; CARDOSO, A.V. Utilização de Resíduos Sólidos da Indústria de Celulose Kraft na Fabricação de Cimento: caracterização físicoquímica. In: CONGRESSO BRASILEIRO DE ENGENHARIA E CIÊNCIA DOS MATERIAIS, 18., Porto de Galinhas, 2008. Anais... Porto de Galinhas, 2008.

Revista Ambiente Construído Associação Nacional de Tecnologia do Ambiente Construído Av. Osvaldo Aranha, $99-3^{\circ}$ andar, Centro Porto Alegre - RS - Brasil CEP $90035-190$

Telefone: +55 (51) 3308-4084 Fax: +55 (51) 3308-4054 www.seer.ufrgs.br/ambienteconstruido E-mail: ambienteconstruido@ufrgs.br

46 Pinheiro, M. L.; Alvarenga, R. de C. S.; Ribeiro, B. C.; Silva Júnior, P. R.; Sarmet, M. S.; Fassoni, D. P. 